\title{
EL MÉtodo CUALITATIVO EN LA TEOLOGÍA FEMINISTA. LA EXPERIENCIA DE LAS MUJERES Y UN DIÁLOGO CON STEPHANIE KLEIN SOBRE SU ESCUCHA *
}

The Qualitative Method in Feminist Theology. The Experience of Women and a Dialogue with Stephanie Klein about her Listening

\author{
Virginia Raquel Azcuy **
}

RESUMEN: En el marco de una investigación en curso sobre el método cualitativo en teología, este artículo se propone mostrar la pertinencia de este método en el ámbito de la teología feminista cristiana, con particular atención a la experiencia de las mujeres. Entre los presupuestos de la reflexión se asume una epistemología feminista, en vistas a la elucidación crítica de la experiencia de las mujeres como elemento clave en el método teológico, de manera que se haga visible el sesgo opresivo del contexto socio-cultural y religioso androcéntrico y las aspiraciones de liberación de las mujeres en él. A su vez se considera la experiencia de la womenchurch o Iglesia de las mujeres como movimiento histórico de solidaridad entre mujeres y con varones, en vistas a una plena liberación de la humanidad. La exigencia de un relevamiento científico de estas experiencias conduce a la necesidad de justificar el valor, la utilidad, y la eficacia de la investigación cualitativa en la teología feminista, con atención a algunos desarrollos representativos en diversos contextos. Junto a otras autoras como Ada María Isasi-Díaz y Rebecca Chopp, se destaca el aporte de Stephanie Klein por mostrar la función sanadora y empoderadora de la "escucha peligrosa" que puede asumir una teología mediada por el método cualitativo, para renovar su discurso a partir de las diversas y dolientes experiencias de mujeres que buscan liberación.

PALABRAS CLAVES: Experiencias de mujeres. Teología feminista. Perspectiva de género. Método cualitativo. Stephanie Klein.

\footnotetext{
* Este texto se enmarca en el proyecto de investigación Fondecyt $\mathrm{N}^{\circ} 1190556$.

** Pontificia Universidad Católica de Chile, Centro Teológico Manuel Larraín, Santiago, Chile
} 
ABSTRACT: In the context of an ongoing study of the qualitative method in theology, the aim of this article is to show the relevance of this method in the field of Christian feminist theology, paying special attention to the experience of women. Among the assumptions of this reflection, a feminist epistemology is taken on in order to provide the critical clarification of the experience of women as a key element in the theological method, making the oppressive biases in the male-centered, socio-cultural and religious context, as well as women's aspiration for liberation within it, visible. Likewise, the experience of the women-church, or Church of the Women, is considered as an historic movement of solidarity between women and men, keeping in mind a full liberation of humanity. The demand for a scientific study of these experiences leads to the need for justifying the value, usefulness, and efficiency of qualitative research in feminist theology, paying attention to some representative developments in different contexts. Together with other authors like Ada María Isasi-Díaz and Rebecca Chopp, Stephanie Klein's contribution stands out. It displays the healing and empowering role of "dangerous listening", which may assume a theology mediated by the qualitative method, to renew its discourse drawing from the painful and diverse experiences of women in search of liberation.

KEYWORDS: Women's Experiences. Feminist Theology. Gender Perspective. Qualitative Method. Stephanie Klein.

\section{A modo de introducción}

$\mathrm{T}$ razar mapas sobre diversas teologías feministas sigue siendo un objetivo prioritario en nuestro contexto sociocultural y académico, plantea la importancia de dar conocer o revisitar las obras de referencia, aunque hayan sido escritas hace algunas décadas (RAIMONDO, 2020). Lo que se busca por esta vía, de alguna manera, no es otra cosa que retomar las preguntas fundamentales acerca de lo que significa el feminismo y su relación con la teología cristiana, la justificación de su originalidad y la determinación de su lugar, auf der Grenze, en el límite o la frontera, entre ciencia y movimiento, conocimiento y autoconocimiento, saber y experiencia. Y, también, al mismo tiempo, la travesía consiste en la acción de poner límites y traspasarlos como algo constitutivo, inspirarse en el encuentro de ciencia y movimiento para constituirse como crítica científica feminista, atravesar con esperanza el límite que separa el patriarcado del feminismo para poder discernir los espíritus en esa frontera (MEYER-WILMES, 1990).

En este horizonte reflexivo trazado por la teóloga alemana Hedwig MeyerWilmes, el presente artículo se propone recuperar algunas cartografías de la década de los años noventa del pasado siglo, en vistas a bosquejar un panorama de epistemología teológica feminista y proponer a la vez un contexto general para el estudio de algunos aportes de otra teóloga alemana, Stephanie Klein, desde la perspectiva del método cualitativo y la teología feminista. En esta década, considerando solo el contexto alemán, norteamericano e hispano/latino y latinoamericano, se publica un con- 
junto de obras monográficas que profundizan en el método de la teología feminista, su relación con la/s experiencia/s de las mujeres y/o el uso de la investigación cualitativa (MEYER-WILMES, 1990, 1996; CHOPP, 2002 [1991], 1995; ISASI-DÍAZ, 1993, 1996; FULKERSON, 1994; KLEIN, 1994; SOMMER, 1998; AQUINO; TAMEZ, 1998). En el marco de esta constelación de autoras de diversos contextos y denominaciones, este texto se focaliza en algunos escritos de la teóloga católica Stephanie Klein, sobre todo de este período y la década siguiente (KLEIN, 2003, 2005), por presentar ellos importantes avances en el cruce entre investigación cualitativa y teología feminista desde la teología práctica y ser probablemente desconocidos en nuestro ámbito. ${ }^{1}$

En el contexto latinoamericano e hispano/latino, la producción teológica feminista también ha dado pasos significativos desde los años noventa $\mathrm{y}$, en particular, en las últimas dos décadas (AQUINO; MACHADO; RODRÍGUEZ, 2002; GARCÍA; VELEZ; VIVAS, 2004; AZCUY; BEDFORD; GARCÍA BACHMANN, 2018b). Junto a estos y otros estudios, se publican algunas obras dedicadas a método teológico con énfasis en la perspectiva de la liberación y su vínculo con la teología feminista (VUOLA, 2000; VELEZ, 2008 [2000]), aunque no se registran monografías que hayan abordado en profundidad de manera conjunta el uso del método cualitativo y la teología feminista. No obstante, se puede hablar de diversas incursiones en torno al método cualitativo en las teologías hechas por mujeres de la región: entre ellas, una monografía sobre ecofeminismo (RESS, 2012 [2003]) y, en la última década, diversos desarrollos grupales vinculados a ciclos de investigación sobre pastoral urbana y otras temáticas actuales (AZCUY, 2018a; VELEZ, 2016b; BECERRA MELO, 2018). También se pueden constatar algunos estudios individuales, que son el fruto de tesis de doctorado o maestría en teología, como los de María del Pilar Silveira, Carolina Bacher Martínez (2017), Susana Becerra Melo (2015) y Catalina Cerda Planas (2019). ${ }^{2}$

En este contexto amplio y floreciente, nutrido especialmente por los aportes provenientes del ámbito norteamericano y europeo, el presente artículo se propone una meta muy precisa que consiste en recuperar y profundizar el vínculo entre la/s experiencia/s de las mujeres y las teologías feministas y examinar, en particular, algunos aportes que utilizan la mediación del método cualitativo en teología dando un relieve particular a los escritos de Stephanie Klein, en diálogo con otras autoras. El objetivo

\footnotetext{
${ }^{1}$ Agradezco a la autora el envío de sus dos obras principales y agotadas (KLEIN, 1994 y 2005). ${ }^{2}$ No se consideran, en esta enumeración, autoras de otras disciplinas que han utilizado y combinado métodos cualitativos y perspectiva de género, entre las cuales sin duda se destaca la labor pionera de Ana María Bidegain en el área de historia y, más recientemente, el aporte conjunto de Ana L. Suárez y Brenda Carranza (sociólogas), junto a Véronique Lecaros (teóloga práctica) en el área de vida religiosa femenina en América Latina.
} 
de este artículo es plantear la pertinencia del método cualitativo para hacer teología feminista a partir de la experiencia de las mujeres, es decir, retomar la cuestión de las experiencias liberadoras de las mujeres como punto de partida de las teologías feministas y valorar la mediación del método cualitativo a la hora de acceder e interpretar las diversas experiencias y voces de mujeres hacia una plena liberación de la humanidad. De este modo, el texto se organiza en dos momentos: en el primero, se presentan los elementos fundamentales de una epistemología feminista en teología, con una aproximación a la experiencia de las mujeres y su tratamiento teológico; en el segundo momento, se dialoga con los aportes sobre método cualitativo en teología feminista en algunos escritos seleccionados (KLEIN, 1994, 2003, 2005 y 2019). La relevancia del tema está unida a su talante inclusivo por vincularse a la responsabilidad propia de la labor de teólogas y teólogos en la actualidad (COSTADOAT, 2005). En el límite entre una visión androcéntrica de la realidad socio-religiosa y el desafío planteado por el feminismo, las mujeres y varones dedicados a la teología encuentran una oportunidad privilegiada de discernimiento.

\section{Aportes sobre epistemología feminista en teología}

Mucho se ha sido dicho y escrito sobre feminismo, pero la resistencia cultural que suscita y permea cada ámbito, incluso el teológico, amerita considerar su comprensión una vez más. Con palabras de Elisabeth Schüssler Fiorenza: "feminismo es la noción radical de las mujeres como seres humanos" (SCHÜSSLER FIORENZA, 2013, p. 7). Se trata, en la visión de la autora, de un concepto radical y una afirmación de sentido común en el siglo XXI, puesto que implica que las mujeres son ciudadanas en sentido pleno. Tal feminismo no se refiere solo al género, sino también a la raza, la clase, el heterosexismo y el imperialismo, es decir, concierne a todas las relaciones de dominación del poder kyriarcal. El concepto "kyriarcado", neologismo acuñado por Schüssler Fiorenza, reemplaza al de patriarcado ampliándolo con referencia al sistema piramidal masculino de estructuras sociales y religiosas de subordinación y opresión, que se encuentra activo en una interseccionalidad multiplicativa de clase, raza, género, etnicidad, imperio y otras estructuras de discriminación. ${ }^{3}$ Feminismo y kyriarcado -o sus parientes- son conceptos claves para introducir lo que se entiende, en general, por teología feminista. Así lo comprende también Meyer-Wilmes, inspirada en el teólogo evangélico Paul Tillich y la escritora y novelista

\footnotetext{
${ }^{3}$ Los conceptos "patriarcado", "androcentrismo" y "kyriarcado" se utilizan de un modo alternativo en este texto, en razón del uso que hacen de ellos las diversas autoras, en obras escritas en distintas décadas, si bien personalmente me inclino al uso del concepto de androcentrismo o fórmulas equivalentes.
} 
alemana-sueca Anja Lundholm, al afirmar el lugar de la teología feminista entre el feminismo y el patriarcado: auf der Grenze, en la frontera (MEYER-WILMES, 1990). Es cierto que, a partir de esta ubicación fundamental, se despliegan distintas corrientes, perspectivas y autoras, surgen diferentes tipologías de acuerdo a su posición frente a la tradición, pero no es posible dar cuenta en detalle de estas características en este estudio cuya finalidad apunta en otro sentido. No obstante, más allá de su pluralidad, las teologías feministas tienen en común que abrazan los aportes del feminismo porque quieren aportar, en cuanto teologías, a la liberación de las mujeres (CHOPP, 1986; VIVAS, 2001). Como ha señalado Nancy Bedford, teóloga argentina residente en EE.UU., los feminismos coinciden en tres afirmaciones centrales: la convicción de que las mujeres no son ontológicamente menos que los varones; una crítica al androcentrismo como cosmovisión por la cual los varones y sus intereses se constituyen en medida y criterio de la realidad y la elaboración de propuestas teológicas constructivas para superarlo (BEDFORD, 2001). Este es el asunto, como muestra la autora, que hace ineludible el uso de la teoría feminista como mediación socio-analítica para formular una teología que sea liberadora para mujeres y varones, pese a la incomodidad y hasta rechazo que el término pueda generar. Cabe preguntarse, en fin, si la resistencia al feminismo no es una constatación evidente del androcentrismo interiorizado culturalmente por siglos.

Como lo han formulado con frecuencia muchas teólogas cristianas, vale la pena reafirmar que el feminismo, cuando se practica desde una perspectiva creyente, viene a dar sentido a dicha opción e incluso descubre en la fe los fundamentos de la liberación humana. La exploración del límite entre tradición androcéntrica y perspectivas liberadoras para las mujeres merece ser considerado en relación con la hermenéutica bíblica feminista, que puede entenderse como un ámbito propio de una visión crítica y constructiva. En la visión de la exégeta norteamericana Phyllis Bird, ${ }^{4}$ la Biblia es al mismo tiempo una fuente de opresión en cuanto texto patriarcal y una fuente de liberación. Con todo, desde su punto de vista, la Biblia es sobre todo "la fuente primaria para una crítica feminista a la opresión patriarcal", a lo cual agrega a continuación, como en una especie de explicitación de sus fundamentos: "soy feminista porque soy cristiana" (BIRD, 1994, p. 70s). Esta convicción, de la cual muchas teólogas nos hacemos eco por sentirnos identificadas, se relaciona con la fe en Cristo, con la verdad que supone saber que ya no hay judío ni griego, esclavo ni libre, varón ni mujer, porque en Él somos uno (cf. Gál 3,28). La teología feminista se afianza en la tensión que supone aceptar una tradición involucrada con formas religiosas de kyriarcado y una fe que proclama la

\footnotetext{
${ }^{4}$ Ministra ordenada de la Iglesia Metodista Unida. Profesora emérita de Antiguo Testamento del Seminario Teológico Garrett, Chicago y profesora de Estudios Bíblicos McCarthy en el Pontificio Instituto Bíblico.
} 
salvación de toda forma de opresión. Se trata, en concreto, de la tensión que supone permanecer en el límite entre el cristianismo y el feminismo, sin renunciar a ninguno de ambos sino sosteniéndolos en diálogo, sin suprimir la confrontación que supone trazar un programa científico para esta conversación, pero descubriendo también que el límite puede ser un espacio de discernimiento entre patriarcado y feminismo, entre teología y feminismo (MEYER-WILMES, 1990, p. 9). La pregunta que se plantea es cómo dar razón de la fe que hay en nosotras, dicho en primera persona: cómo dar cuenta de la experiencia liberadora que constituye la fe en Jesucristo para mí como mujer $\mathrm{y}$, formulado en tercera persona, cómo releer historias de vida de mujeres actuales en diálogo con historias de mujeres en los textos bíblicos (BEDFORD, 2001; VIVAS, 2001). La respuesta de la teología feminista, que busca poner límites al kyriarcado y superar la experiencia de la opresión de las mujeres mediante la fuerza que surge de la rebelión en el límite, según la expresión de Hedwig Meyer-Wilmes, da lugar al surgimiento de discursos de emancipación que anuncian la Palabra con la esperanza de una transformación del patriarcado hacia la libertad y la liberación, mediante una lectura crítica y feminista (CHOPP, 2002, 1986).

Siguiendo la sugerencia de Meyer-Wilmes, vale la pena explorar la doble ubicación de la teología feminista desde otro punto de vista: "ella es reflexión orientada hacia la teología y hacia el feminismo como análisis social, y es parte de un movimiento de mujeres dentro y al margen del cristianismo" (MEYER-WILMES, 1996, p. 13). Su planteo lleva directamente a la consideración de la cuestión de género como parte importante en la comprensión de la teología feminista, por cuanto los estudios de género, nacidos en el ámbito de la teoría feminista, inauguran una perspectiva que hace de la teología que la utiliza un discurso crítico capaz de lidiar con la subordinación, la opresión y la dominación masculina en las representaciones y relaciones de género. Coincido con otras teólogas al pensar que la categoría de género constituye una herramienta teórica indispensable para evidenciar las tramas oculta(da)s de la injusticia y la desigualdad basadas en las diferencias sexo-genéricas y en otras formas de opresión que generan discriminación, violencia $y$, en casos extremos, hasta feminicidio (AQUINO; TAMEZ, 1998; BEDFORD, 2001). De acuerdo con otras estudiosas, considero que no existe una "ideología de género", sino una "perspectiva de género", surgida y desarrollada en el marco de los debates feministas, que funciona como instrumental analítico y se asume con la finalidad de visibilizar y desmantelar las distintas formas de la opresión androcéntrica y kyriarcal (AQUINO; MACHADO; RODRÍGUEZ, 2002; BEDFORD, 2005; VELEZ CARO, 2008; AMMICHT-QUINN, 2012, 2017). Entre los avances y aportes de la teoría feminista, también se cuenta el paradigma de la interseccionalidad, que ya está calando hondo en un amplio sector de la producción teológica feminista (FULKERSON; BRIGGS, 2012; PINEDA-MADRID, 2017; KLEIN, 2019). En efecto, las teologías feministas 
han ido ampliándose en diversas intersecciones que han dado lugar a nuevos enfoques como estudios queer, estudios postcoloniales, estudios de masculinidades o crítica bíblica de las ideologías, lo cual ya no permite estar actualizada o actualizado en el área en la cual se despliega el trabajo bíblico o teológico (SCHÜSSLER FIORENZA, 2013, p. 5).

La doble localización de la teología feminista, entre la teología y el feminismo como instrumento de análisis social, incluye además la frontera entre la teología y el movimiento feminista, tal como lo propone Hedwig Meyer-Wilmes: "localizo la teología feminista en el límite entre movimiento y ciencia; no porque no pueda decidirme, sino porque este límite marca su autocomprensión" (MEYER-WILMES, 1996, p. 13). De tal manera que el uso del instrumental analítico de la teoría feminista, no se separa del movimiento feminista de mujeres, sino que mantiene viva la conexión con las experiencias de mujeres y sus luchas de liberación. Un feminismo teológico con perspectiva de género o interseccional no busca otra cosa que ejercer una crítica liberadora hacia aquellas formas discursivas y prácticas de dominación injusta de unos seres humanos sobre otros y sobre la creación, proponiendo una nueva forma de convivencia. En el cumplimiento de este cometido, la teología feminista apela a la "experiencia de las mujeres", como desde los años ochenta lo han planteado las obras pioneras de Rosemary Radford Ruether, Sexism and God-Talk (1983) y Elisabeth Schüssler Fiorenza, In Memory of Her (1983). Según Radford Ruether, se trata de asumir la experiencia de las mujeres y no meramente la experiencia humana: "la unicidad de la teología feminista no se apoya en su uso del criterio de la experiencia sino más bien en su uso de la experiencia de las mujeres, que ha estado casi enteramente excluida de la reflexión teológica en el pasado" (RUETHER, 1993 [1983], p. 13). Ya hace casi cuatro décadas, la teóloga católica hacía el planteo fundamental al sostener que "el uso de la experiencia de las mujeres en la teología feminista, por lo tanto, explota como una fuerza crítica, exponiendo a la teología clásica, incluyendo sus tradiciones codificadas, como basadas en la experiencia masculina más que en la universal experiencia humana" (RUETHER, 1993, p. 13). De este modo, para esta pionera, la teología feminista hacía visible una sociología del conocimiento teológico, que ya no puede quedar ocultado bajo pretendidas formas de objetividad y autoridad universal. Queda planteado el desafío de una hermenéutica crítica y feminista frente a la tradición cristiana con su sesgo androcéntrico (KLEIN, 1994, p. 65). En la recepción del planteo de Radford Ruether, se puntualiza que la novedad de la teología feminista no se encuentra en el recurso a la experiencia de las mujeres, sino en la recuperación de aquellas experiencias que la teología cristiana olvida y debería prestar atención para probar sus hallazgos; asimismo, se señala que asumir experiencias de las mujeres como punto de partida implica afrontar cuestiones filosóficas y teológicas asociadas con lo universal y lo 
particular de estas experiencias, como se aborda a continuación. Stephanie Klein realiza algunas observaciones sobre este punto, al afirmar la actualidad puesta de manifiesto en la consideración de la experiencia de las mujeres y precisar que se trata sobre todo de aquellas mujeres que han sufrido o sufren violencia (KLEIN, 2003). En este contexto, se manifiesta la centralidad de las experiencias de mujeres en el método de la teología feminista contemporánea y la pertinencia del uso del método cualitativo para el relevamiento de estas experiencias desde el punto de vista de sus protagonistas. La teología feminista define su ubicación teológica en diálogo con el feminismo teórico y práctico, la dimensión práctica le pertenece por cuanto asume una pretensión crítica y transformadora (MEYER-WILMES, 1990, 1996; VELEZ, 2008, 2016b). La experiencia liberadora de las mujeres se vincula, ciertamente, con los desarrollos de las teologías de la liberación y con el talante liberacionista de las diversas teologías feministas, pero también encuentra sus fundamentos en las enseñanzas del Concilio Vaticano II sobre el reconocimiento de la dignidad humana (KLEIN, 1994, p. 60; VELEZ, 2016a). Las teologías feministas cristianas, nacidas y sostenidas en el límite entre feminismo y kyriarcado, tradición cristiana y experiencia, teología y feminismo, ciencia y movimiento, son también un producto teológico de la recepción conciliar en la lectura de los signos de los tiempos y la promoción de la dignidad de las mujeres.

\subsection{La experiencia de las mujeres (hispanas) que buscan liberación}

Un interesante estudio de Serene Jones (Yale Divinity School) sobre los dos modos de considerar la "experiencia de las mujeres" por parte de las teologías feministas, womanistas y mujeristas en Estados Unidos puede servir de introducción en este punto (JONES, 1997). Con él, la autora salía al paso de un tema principal en la teología feminista como su fundamentación en la experiencia de las mujeres, lo cual planteaba la cuestión central de "la mujer", la crítica al esencialismo y la realidad de las mujeres en sus diferencias, el alcance universal y el valor particular de sus experiencias. Precisamente, para Jones, la posición metodológica que seguían las autoras en este tema permitía organizarlas en dos grupos: el primero fue caracterizado por su tendencia a la universalización y/o a las perspectivas históricas en referencia a la estructura de la experiencia humana. Entre sus representantes, la autora mencionaba a teólogas que asumen una perspectiva fenomenológica como Elizabeth Johnson y Catherine LaCugna, las que siguen una línea psicoanalítica como Rita Brock y Katherine Keller y las teólogas que explotan la clave literaria/textual como Delores Williams y Sallie McFague. En el balance de este grupo, Jones señalaba que estas diversas propuestas fundan sus proyectos sobre el rock place de lo universal, por lo cual son especialmente aptas para trabajar en el ámbito de la teología dogmática o de las doctrinas cristianas, a la vez que son más débiles en 
la recuperación de las experiencias de mujeres que quedan subsumidas en categorías fenomenológicas, procesos metafísicos, visiones del psicoanálisis o la narrativa literaria (JONES, 1997, p. 46s, 52s).

El segundo grupo propuesto por Serene Jones está tipificado por evitar la universalización de manera consciente y optar, en cambio, por la "descripción densa" de experiencias situadas históricamente y especificadas culturalmente, lo cual se identifica con el hard place de lo particular. Se especifican, además, dos subgrupos: primero, las teólogas que utilizan herramientas de la antropología cultural para localizar la experiencia como Kathryn Tanner y Ada María Isasi-Díaz y, segundo, las que emplean el post-estructuralismo como Rebecca Chopp y Mary McClintock Fulkerson, entre otras. En la caracterización de Jones, se trata de propuestas suficientemente sólidas, aunque sus formulaciones son menos estables que las del grupo volcado a diversas formas de universalización. En el caso del libro En la lucha de Ada María Isasi-Díaz ${ }^{6}$ (1993), se intenta un análisis teológico liberador de la experiencia vivida de una comunidad, con atención a las prácticas culturales y los lenguajes religiosos. El foco es la experiencia de las mujeres latinas en EE.UU. y, para Jones, su interés de evitar la universalización se puede observar en la cualidad de mosaico que presenta el texto al reunir "las piezas de las diversas voces de las mujeres hispanas que ella entrevista y de las diferentes teorías sociales que ella utiliza para situar sus vidas" (JONES, 1997, p. 49). En la lectura que Jones hace de Isasi-Díaz, lo que más se destaca es precisamente que, en ese mosaico de voces, permanece viva la experiencia de las mujeres, sin ser forzada a entrar en un esquema de análisis o un significado textual particular. El logro de la teóloga cubana se observa en su capacidad de no eclipsar las diferencias sustantivas entre las latinas y, al mismo tiempo, en su identificación de aquellos "temas generativos" compartidos como son las concepciones de "proyecto histórico" o "mestizaje", que sirven de base para lo común y la visión liberadora. Tales temas ofrecen, sin duda, una clave hermenéutica para la interpretación teológica de diversos aspectos como la agencia moral, la verdad y la diferencia. Al concluir su análisis

\footnotetext{
${ }^{5}$ Mary McClintock Fulkerson nació en 1950 y es profesora emerita de la Duke Divinity School de la Iglesia Metodista Unida. Su contribución sobre la epistemología feminista liberadora y la práctica del método etnográfico en teología feminista amerita un estudio detenido que no es posible en este artículo. En la monografía Changing the Subject. Women's Discourses and Feminist Theologies (Eugene, OR 2001 [1994]) realiza una crítica a la pretendida universalidad de la experiencia de las mujeres, para proponer un análisis teológico feminista del discurso de las mujeres que asuma situaciones, diferencias y múltiples identidades. Su aplicación de la etnografía en Places of Redemption. Theology for a Wordly Church (Oxford 2007) se inscribe en el horizonte de una eclesiología etnográfica.

${ }^{6}$ Ada María Isasi-Díaz (1943-2012) nació en La Habana, Cuba, fue misionera en Lima, Perú (1967-1969), obtuvo su doctorado en teología en 1990 y fue profesora de Ética en la Facultad de Teología de Drew, EE.UU. Se destaca por su labor pionera en el ámbito de la Hispanic Theology y la Mujerista Theology (AZCUY, 2003).
} 
sobre Isasi-Díaz, Jones deja planteados sus interrogantes en torno a la debilidad en la formulación de doctrinas o desarrollos teológicos sistemáticos (JONES, 1997, p. 52-53).

Con respecto a los métodos utilizados en la teología mujerista por Isasi-Díaz, ella misma hace referencia a las teorías de la ethno-methodoly, la ethnography y la meta-ethnograhpy (ISASI-DÍAZ, 1993; AZCUY, 2003). En el marco de este artículo, interesa destacar el aporte de la etnografía, por tratarse de uno de los enfoques del método cualitativo y el más usado por la teología mujerista (AMEIGEIRAS, 2012; FLORES, 2013; ISASI-DÍAZ, 1993, p. 82). Siguiendo a Jerome Kirk y Marc L. Miller, Isasi-Díaz sostiene que la meta de este enfoque es observar grupos humanos en su propio territorio e interactuar con ellos en su propio lenguaje y de acuerdo a sus costumbres. Ella considera que, entre los diferentes enfoques de la investigación cualitativa, la etnografía es uno particularmente apto para su teología porque ella conduce la indagación a través de la compleja relación que se da entre quien investiga y quien informa. La teóloga cubana propone que "la investigación cualitativa, al igual que la teología mujerista se centra en la vida cotidiana de la gente y busca saber cuáles son las explicaciones que la misma gente tiene de eventos culturales y sociales" (ISASI-DÍAZ, 1993, p. 81). En la aplicación de la etnografía, la autora menciona, en primer lugar, el recurso a las entrevistas etnográficas: "nuestro fin no es el aprender acerca de las mujeres hispanas sino aprender de ellas, es dejar que ellas nos enseñen" (ISASI-DIAZ, 1993, p. 82). En este proceso, se esclarece el elemento liberador de esta teología, que puede entenderse como parte de la búsqueda de una etnografía liberacionista, extendida en la teología feminista y entre otras/os estudiosas/os que buscan producir etnografías como impulso de liberación humana. Lo interesante, en la teología mujerista es que las teólogas asumen el lugar de observadoras-participantes, por medio de la observación participante y la reflexividad, en busca de liberación tanto de investigadoras y escritoras como de mujeres hispanas (ISASI-DÍAZ, 1993, p. 83).

En la propuesta de esta teología, mediada especialmente por la etnografía, las dimensiones de lo universal y lo particular merecen ser todavía consideradas. Por una parte, Ada María Isasi-Díaz se entiende a sí misma como "una teóloga activista comprometida con la lucha por la justicia y la paz", que busca contribuir y participar "en la lucha por la liberación" de las mujeres hispanas en Estados Unidos (ISASI-DÍAZ, 1993, p. xvii; 1996, p. 59). Por otra parte, ella explica cómo entiende esta tarea con respecto a sus hermanas: "No todo el lenguaje que empleo es conocido por las mujeres hispanas de la base, pero creo que lo que digo no traiciona lo que ellas creen y practican, quienes ellas son; aunque yo no hablo por ellas, no me proclamo voz representativa de las latinas, sí hablo con ellas y en favor de ellas" (ISASI-DÍAZ, 1993, p. xviii). Si bien es verdad que la autora 
se circunscribe a un grupo particular de mujeres hispanas, este hecho no le impide una cierta mirada hacia lo universal, con una precaución metodológica -que pide ser aclarada- de mantener vivas las diferencias que emergen entre las voces de estas mujeres:

"creemos que las voces de estas hispanas tienen validez en sí y no necesitan ser representativas para señalar la realidad de las mujeres hispanas. En vez de presentar una voz universal hemos tratado de señalar lo universal siendo muy particulares y específicas. La teología mujerista argumenta que las voces de mujeres hispanas específicas encierran en sí la realidad de todas las hispanas" (ISASI-DÍAZ, 1993, p. 80).

En este señalar lo universal en lo particular, la autora recurre a la meta-etnografía, que define como un método interpretativo que busca una síntesis de conocimiento sin suprimir las diferencias, sino relacionando de manera holística los distintos elementos entre sí en lugar de referirlos a una clasificación general impuesta desde afuera (ISASI-DÍAZ, 1993, p. 68ss). Sin duda, este aporte teológico etnográfico resulta muy inspirador, aunque permanecen algunos interrogantes con respecto al alcance del momento interpretativo en su propuesta. Su valor estriba, precisamente, en haberse adentrado en el uso del método cualitativo, con una perspectiva feminista que asume la denominación mujerista, para conocer las experiencias de las mujeres hispanas y recuperar sus voces sobre sus luchas de liberación en lo cotidiano.

\subsection{Women-Church o la experiencia (feminista) de las mujeres en la Iglesia}

Para completar la caracterización del segundo grupo de autoras propuesto por Serene Jones (1997), vale la pena explorar el tema de la experiencia de las mujeres en relación con la vida eclesial desde algunos aportes de Rebecca Chopp.7 Al respecto, Chopp resume su óptica al afirmar que "la realidad de la Iglesia en el cristianismo feminista liberador es denominada a menudo como 'mujeres-iglesia' [women-church]" (CHOPP, 1995, p. 51). En sentido histórico, el fenómeno women-church se origina en Estados Unidos, a principios de los años ochenta del siglo $X X$, vinculado al reclamo de la ordenación de mujeres, como alternativa a la práctica religiosa del patriarcado y designa el movimiento global de comunidades feministas de base y grupos de mujeres comprometidas ad hoc para redefinir iglesia a través de rituales creativos, soporte mutuo y nueva espiritualidad emergente. Entre las primeras voces que trataron el tema se encuentra Elisabeth Schüssler

\footnotetext{
${ }^{7}$ Rebecca Chopp nació en Kansas (1952). Pastora y teóloga metodista. Fue Decana de la Facultad de Teología en la Candler School of Theology at Emory University (1993-1997) y en la Yale University (2001-2002); Rectora en la Colgate University (2002-2009) y del Swarthmore College (2009-2014); Chancellor en la University of Denver (2014-2019).
} 
Fiorenza, quien ya en 1982 formuló la idea de una ekklesia gynaikon, iglesia de las mujeres, cuya encarnación histórica debía encontrarse en la vida de mujeres católicas (SCHÜSSLER FIORENZA, 2000 [1983]). Diann Neu tradujo el término como women-church, el cual fue asumido por el movimiento de mujeres católicas en 1983 y reflexionado teológicamente por R. Radford Ruether, en diálogo con comunidades litúrgicas feministas y las experiencias de mujeres marginadas en la Iglesia (MEYER-WILMES, 1990; CHOPP, 2002, 1995). Como balance, sirve esta apreciación: "desde entonces, el término ha sido utilizado ampliamente para significar que la realidad de las mujeres -experiencias, relaciones, prácticas- es, ha sido y será Iglesia" (CHOPP, 1995, p. 51). En la formulación de Radford Ruether, la women-church puede entenderse como una "religión o espiritualidad feminista" que reconoce "la necesidad de comunidades de fe y liturgia" y de "símbolos profundos y acciones simbólicas que guíen e interpreten la experiencia actual del tránsito del sexismo a la humanidad liberada" (RUETHER, 1985, p. 3). El talante comunitario y transformativo del planteo frente al sistema androcéntrico queda a la vista y constituye un tópico preferente de la teología feminista.

El movimiento women-church no se entiende a sí mismo como cismático y su foco no es tanto proveer de una plataforma de diálogo con la Iglesia establecida, sino ofrecer un espacio para que las voces de las mujeres puedan ser escuchadas y en el cual ellas puedan empoderarse para ser Iglesia desde su situación. Rebecca Chopp retoma la experiencia de mujeres-iglesia y la vincula al planteo de una reconstrucción de la Iglesia como comunidad de transformación emancipadora. Entre las experiencias eclesiales que constituyen signos en este camino de reforma, se encuentra "la realidad de las mujeres en la iglesia, las posibilidades de la mujeres-iglesia, el sueño de las mujeres de una iglesia que sea igualitaria y que incluya a las mujeres, reconozca sus voces, sane sus heridas y celebre sus deseos" (CHOPP, 2002, p. 74s). Según esta autora, la women-church no es solo para mujeres, sino para mujeres y varones que estén dispuestos a escuchar la Palabra, recibir su visión y hablar juntas/os palabras de transformación emancipadora (CHOPP, 2002, p. 76-77). En palabras de Ruether, es una iglesia en éxodo, que camina en una perspectiva liberadora de la humanidad (RUETHER, 1985, p. 57ss). Para Chopp, la women-church designa una realidad ya presente, más allá de los límites denominacionales: "la ekklesia existe donde el Espíritu está presente, donde el Espíritu trabaja a través de la vida de mujeres y varones para la realización de una nueva vida para todos, incluyendo la tierra" (CHOPP, 1995, p. 51).

En su obra Saving Work, la pastora y teóloga metodista Rebecca Chopp avanza su análisis a través de la consideración de tres prácticas concretas vinculadas a la experiencia de las mujeres: la práctica de la narración, la práctica de la Iglesia y la práctica de la teología, de las cuales -conforme 
al tema de este artículo- reviste especial interés la primera. Al respecto, Chopp sintetiza su visión:

Las prácticas feministas de educación teológica crean una agencia narrativa en el doble sentido de crear un espacio para el desarrollo de una agencia y mediante composición de narrativas particulares para el florecimiento personal y social. Sin duda, en mi experiencia, por medio de prácticas feministas de educación teológica, las mujeres crean una nueva experiencia de subjetividad. Mujeres y varones escriben nuevas narrativas para sus vidas y, en este proceso, crean nuevas formas de agencia narrativa (1995, p. 34).

Acerca del proceso por medio del cual la teología feminista posibilita esta agencia, la autora señala algunos caminos que resume en cuatro puntos básicos (CHOPP, 1995, p. 34ss): 1. Nombrar o dar voz a las experiencias de las mujeres, para lo cual Chopp recuerda los aportes de R. Radford Ruether y Nelle Morton -cuya consideración se retoma en la segunda parte de este artículo-; al nombrar sus experiencias, las mujeres comienzan a narrar su significado en maneras nuevas. 2. Privilegiar contextualidad y diferencia por encima de universalismo y esencialismo, en respuesta a que las mujeres no son iguales, sino que son afroamericanas, lesbianas, hispanas, etc. La agencia narrativa de la teología feminista no puede fijarse en la universal abstracción de la experiencia blanca, de clase media y heterosexual, sino en una pluralidad de voces y experiencias de opresión, tal como también han detallado Isasi-Díaz (1996, p. 108ss) y Fulkerson (1994, p. 13ss). 3. Reconstruir la tradición, tanto en relación con las Escrituras como con respecto al sistema de símbolos, para superar la visión patriarcal o androcéntrica; en esta tarea, la autora remarca el aporte de la interpretación feminista de la Biblia y la actividad reconstructiva de las mujeres como lugar de la reflexión cristiana sobre Dios. 4. Crear una agencia moral y una ética feminista de virtudes, con los aportes de autoras pioneras en este campo como Katie Cannon o Beverly Harrison. En conclusión, como la educación incluye un ámbito de formación de la subjetividad, la educación teológica feminista puede ofrecer a mujeres y varones un espacio de construcción narrativa por medio de tres elementos: imaginación, justicia y diálogo. Imaginación para nuevos roles, historias y modelos; diálogo para hablar, escuchar y ser escuchado, imaginación y diálogo son necesarias juntas en las prácticas feministas de narratividad; justicia, que implica deliberación, representación y construcción dentro de la comunidad, es decir, que cada una y cada uno tenga voz en su autodeterminación y sea animada/o para escribir su propia historia.

Si bien R. Chopp no ha trabajado con método cualitativo en su teología, sí ha asumido el giro hacia la práctica a partir de la teología de la liberación y la teología política, al modo de una critical praxis correlation en solidaridad con las víctimas (CHOPP, 1986, p. 139ss). Desde su práctica teológica feminista, ha constatado la profundidad, el poder y el potencial transformativo de las mujeres en las iglesias, así como la estrecha relaci- 
ón entre teología feminista y movimiento feminista en el cristianismo en vistas al sueño de una transformación del patriarcado hacia la libertad de toda la humanidad (CHOPP, 1995, p. 4). Bajo el impulso de la praxis y gracias a su experiencia como pastora, la autora reflexiona sobre el aporte del movimiento feminista blanco en la Iglesia Metodista Unida en vistas a que las voces de las mujeres en los márgenes puedan ser escuchadas en el centro, una escucha que posibilita que la Palabra de Dios sea escuchada en la vecina y el vecino. Se destaca su valoración de las experiencias de las mujeres como "comunidad de transformación emancipadora" y "lugares de gracia" (CHOPP, 2002, 1995).

\subsection{La teología feminista entre voces y relatos de mujeres}

La contribución de Ada María Isasi-Díaz muestra cómo el uso de la etnografía en la teología feminista puede posibilitar la superación de una pretensión inadecuada con la que tropieza, una y otra vez, quien hace teología: erigirse como voz de quienes no tienen voz. A cambio de esto, la propuesta de la teología mujerista es amplificar las diversas voces de las mujeres hispanas o latinas y valorarlas en sí mismas, buscar una síntesis sin pretender generalizar. La etnografía practicada por Isasi-Díaz puede entenderse como una etnografía liberacionista y, en este sentido, como una teología feminista de liberación, que se comprende a sí misma como praxis de liberación. Lo novedoso es el elemento autoimplicativo: la/s teóloga/s se incluye/n en el proceso de liberación, junto a las mujeres hispanas que hablan de sus luchas en la vida cotidiana. La opción de la autora por las voces de hispanas tiene prioridad y esto mismo podría defraudar a quienes esperan mayor elaboración teológico sistemática en los resultados de la investigación (AZCUY, 2018a).

En el caso de Rebecca Chopp, quien no asume el método cualitativo como forma específica de hacer teología, se da un aporte de valor semejante en cuanto prioriza la práctica de la narración como una de las claves en la propuesta de una educación teológica feminista y lo hace en relación con la práctica de las mujeres en la iglesia. El otro énfasis importante de sus escritos está dado por la relación de estas prácticas feministas con las Escrituras en vistas a una nueva imaginación en discursos teológicos emancipatorios para la humanidad. En su visión, la agencia narrativa de las mujeres puede ser un camino transformativo para la superación del androcentrismo en las relaciones humanas. En solidaridad con las víctimas, esta teología feminista elige el lugar de los márgenes para practicar la escucha y se enfoca en la construcción de la justicia en las comunidades cristianas como punto de partida de un anuncio renovado de la Palabra para la humanidad.

Con acentos diferentes, las dos teólogas muestran caminos concretos al asumir la experiencia de las mujeres: Isasi-Díaz como teóloga mujerista y 
etnógrafa, dando prioridad a las voces de las mujeres hispanas y al horizonte religioso-cultural latino en EE.UU.; Chopp como teóloga feminista práctica, articulando la agencia narrativa con el discurso teológico, en la perspectiva del movimiento mujeres-iglesia. El esfuerzo de ambas autoras y de tantas otras que como ellas buscan auscultar la Palabra de Dios en las experiencias de las mujeres abre el puente hacia el uso del método cualitativo (CHOPP, 2002; CANALES, 2014; KLEIN, 1994, 2003).

\section{Pertinencia del método cualitativo en teología feminista}

\subsection{La investigación cualitativa en teología (práctica)}

Método cualitativo designa una serie de enfoques metodológicos que estudian la naturaleza profunda de los fenómenos sociales, sus sistemas y estructuras, sus dinámicas internas; intentan comprender el comportamiento humano y sus manifestaciones concretas, y buscan la comprensión y el sentido de las mismas con la participación de las actoras y actores en el proceso de la investigación social (FLORES G., 2009). Los diferentes enfoques, orientaciones y tradiciones que hacen parte de la investigación cualitativa permiten describirla como un proceso multimetódico en su acceso a una variedad de materiales empíricos e interpretativo en cuanto busca construir una imagen compleja y holística de una situación natural desde la perspectiva de los informantes. Su caracterización como mosaico de perspectivas puede incluir estas escuelas: 1 . la teoría fundamentada de datos; 2 la etnometodología y el análisis de la conversación, del discurso y de género; 3 . El análisis narrativo; 4 . La hermenéutica objetiva y la sociología del conocimiento hermenéutico; 5 . La fenomenología y el análisis de pequeños mundos de vida; 6 . La etnografía; 7 . Los estudios culturales, y 8. Los estudios de género. Una cuestión decisiva en los métodos cualitativos es el paso de una epistemología del sujeto cognoscente -propia de quien investiga- a otra del sujeto conocido -correspondiente a quien informa-, para lograr un modo cooperativo e interactivo en la producción del conocimiento (VASILACHIS DE GIALDINO, 2012, p. 58). Conforme a los diversos enfoques o perspectivas cualitativas, se utilizan diferentes técnicas que son procedimientos o recursos como la observación, la entrevista, la historia de vida y los focus groups o grupos focales (FLORES G., 2009). Este abreviado punto de partida da lugar a la consideración del método cualitativo en la teología, cuya naturaleza es diversa a la metodología cuantitativa en las ciencias sociales, aunque el uso de ambas formas de investigación sea complementario en las diversas áreas de estudios empíricos, incluida la teología (CERDA-PLANAS, 2019). En este artículo, se ejemplifica de modo breve con el enfoque etnográfico y sus técnicas con el caso de A. M. Isasi Díaz y, en esta sección, in extenso con el método 
biográfico o de historia de vida según los aportes de Stephanie Klein, con énfasis en teología feminista.

La incorporación del abordaje cualitativo en teología ha tenido lugar en las últimas tres décadas y hace parte de un abanico de diferentes disciplinas que han empezado a utilizar estos métodos marcando un giro general hacia la práctica y hacia la vida (KLEIN, 1994; WARD, 2012). ${ }^{8}$ Según Stephanie Klein, en el contexto alemán, la Biographieforschung o investigación biográfica -uno de los enfoques cualitativos- se dedica a cuatro núcleos de interés: 1. diversos aportes sobre el lugar teológico de la reflexión o narración biográfica; 2 . gran cantidad de contribuciones sobre la biografía como narración o la pragmática narrativa; 3 . otros aportes dedicados a la función de la reflexión y la narración biográfica para la construcción de identidad; 4 . atención prioritaria de las historias de vida en campos prácticos de acción eclesial y cristiana, sobre todo en las áreas de pedagogía de la religión, formación de adultos, homilética y acompañamiento espiritual (KLEIN, 1994, p. 103ss). En la visión de la autora, la investigación biográfica empírica se manifiesta relevante y adecuada para una teología orientada a la praxis, contextual y vinculada a la experiencia, por cuanto abre un acceso complejo a la realidad subjetiva y social humana y, por esta vía, posibilita la comprensión de las experiencias de fe en su contexto y con sus diferencias (1994, p. 12). En esta monografía, Klein se focaliza, a nivel teórico, en análisis del relato y hermenéutica estructural que describe como prácticas investigativas -o técnicas- con mayor desarrollo teórico y, a nivel empírico, en la historia de vida de una mujer considerada desde la perspectiva del estudio de caso en teología (KLEIN, 1994); en este artículo, se pone el foco en los fundamentos teóricos.

También en el área de teología práctica, en el ámbito angloparlante, puede ser ilustrativa la obra de John Swinton; Harriet Mowat, Practical Theology and Qualitative Research (London 2006). Los autores introducen la investigación cualitativa con la analogía de una historia de detective, por los aspectos ínfimos y el proceso complejo de esta forma de conocimiento, que busca ser rigurosa, minuciosa, exacta, compleja y difícil, a la vez que requiere un amplio ramo de herramientas técnicas e idoneidad en interpretación (SWINTON; MOWAT, 2006, p. 30). Swinton y Mowat sugieren que la investigación cualitativa es una herramienta de complejización, que habilita a teólogas y teólogos (prácticos) para ganar visiones profundas y enriquecidas sobre la naturaleza de situaciones y las formas de práctica que son

\footnotetext{
${ }^{8}$ Regina Sommer ha destacado las áreas de teología práctica y teología feminista para el uso del método cualitativo (SOMMER, 1998). También cabe destacar, como área emergente y novedosa, el campo de la eclesiología y los estudios congregacionales, junto a la ética y la espiritualidad; sirve como referencia la red de investigación sobre Ecclesiology \& Ethnography, utilizando "etnografía" para designar los distintos enfoques de la investigación cualitativa (WARD, 2012, p. 6), con investigadores de Estados Unidos y Gran Bretaña, en un ámbito marcadamente ecuménico.
} 
performatizadas en ellas. A su vez resulta evidente que existen tensiones con respecto a la epistemología y los modos en que las dos disciplinas definen la realidad. En la opinión de los autores, el método de correlación según Paul Tillich, que pone situaciones en conversación dialéctica con cosmovisiones de la tradición cristiana y perspectivas planteadas desde otras fuentes de conocimiento como las ciencias sociales, muestra su debilidad en relación con la idea de conversación mutua: “¿cómo puede un sistema de conocimiento creado por seres humanos desafiar a un sistema de conocimiento que reclama ser dado por Dios?" (SWINTON; MOWAT, 2006, p. 83). Swinton y Mowat exponen la dificultad con mayor claridad: si bien en el método de correlación crítica mutua la conversación parece ser mutua, en la práctica la teología fácilmente colapsa ante las ciencias sociales. ${ }^{9}$ Desde el punto de vista de los autores, "la correlación crítica mutua [mutual critical correlation] es algo que teólogas y teólogos buscan, no así etnógrafas y etnógrafos" y se enfatiza, con mucho acierto, que "teólogas y teólogos que desean usar la etnografía como parte de su teologización deben acercarse al tema en cuanto teólogas y teólogos" (SWINTON; MOWAT, 2006, p. 87). Se trata, en mi opinión, de un punto central en el uso de la investigación cualitativa en teología: qué intereses mueve a cada una de las partes y bajo qué condiciones y en qué modalidad puede ser factible y viable un diálogo interdisciplinario entre teología y ciencias sociales (AZCUY, 2003; 2018a; SCHICKENDANTZ, 2017).

Sin duda, el acento puesto por Swinton y Mowat en el elemento teológico de la conversación se presenta como muy significativo al poner en claro que las teólogas y los teólogos que incorporan métodos cualitativos no dejan de lado su punto de vista teológico, sino lo explicitan para enriquecer su propia aproximación metodológica a las prácticas cristianas concretas. En este contexto, más allá del modelo de correlación, los autores sugieren integrar situaciones, teología e investigación cualitativa desde la hospitalidad como actitud: incorporarla en el método permite que la teóloga o el teólogo puedan crear un contexto en el cual la voz proveniente del uso del método cualitativo puede ser escuchada, respetada y tomada con seriedad, pero sin ninguna asunción a priori como que la teología necesita para aceptar plenamente la perspectiva de la realidad que ofrece la investigación cualitativa (SWINTON; MOWAT, 2006, p. 91). En la visión de Swinton, esta perspectiva llega a ser una propuesta metódica de teología práctica: "la relación entre teología y ciencias sociales podría ser mejor resumida por medio de la metáfora de la hospitalidad que de la correlación" (SWINTON, 2012, p. 91). Con esta opción, el autor parece salir al cruce de las exigencias mutuas que plantea

\footnotetext{
${ }^{9}$ El método de correlación, descripto por Paul Tillich en el primer volumen de su Teología Sistemática, describe de modo funcional u operacional, el nexo entre filosofía y teología como el que se establece entre pregunta y respuesta. Según este método, la teología se valida científica y culturalmente sólo como búsqueda de respuestas a preguntas y problemas que surgen de un determinado momento cultural y que explicita la filosofía.
} 
un método interdisciplinario cuando este debe ser puesto en práctica entre una teóloga o teólogo y una investigadora o investigador social. En cambio, cuando la incorporación de la investigación cualitativa en teología depende de las competencias y habilidades de una misma teóloga o teólogo, tal vez puede ser más oportuna la indicación de Elizabeth Phillips: "muchos teólogos y teólogas están hablando sobre hacer etnografía mucho más que haciendo etnografía" (PHILLIPS, 2012, p. 100)..$^{10}$ Se puede conjeturar que el nivel de experticia que supone trabajar con métodos de investigación cualitativa -así como cuantitativa- en teología es una de las razones por las cuales su puesta en práctica resulta todavía poco extendida en el ámbito latinoamericano. Tal puede ser el caso de los estudios de casos, la investigación acción participativa o la combinación de diversos enfoques empíricos, cuyo uso comienza a visibilizarse en la región (AZCUY, 2016, 2018a; VELEZ, 2016b; BACHER, 2013, 2017; CERDA-PLANAS, 2019).

\subsection{El método cualitativo en la teología feminista}

La teología feminista es una de las áreas en las cuales se implementa la investigación cualitativa, sobre todo con un enfoque biográfico y en combinación con la teología práctica, como señalan Stephanie Klein y Regina Sommer. En contexto angloparlante, con preferencia del enfoque etnográfico, este estudio destaca a Ada María Isasi-Díaz, Mary Judith Ress y Mary McClintock Fulkerson: una en el área de ética, otra en ecofeminismo latinoamericano y la tercera como sistemática con orientación práctica. En el Reino Unido, cabe mencionar a la teóloga anglicana Nicola Slee con una labor realmente pionera, diversas investigaciones monográficas desde 2004 y libros en coedición en 2013 y 2018, en una serie dedicada a teología práctica, pastoral y empírica. En América Latina, podría destacarse el trabajo pionero de Susana Becerra Melo (2015).

\subsubsection{La experiencia de opresión y liberación de las mujeres y su "memoria peligrosa"}

En su obra Teología e investigación biográfica empírica, Stephanie Klein plantea el interés de este aporte de las ciencias sociales para el acceso a historias de vida e historias de fe, para la relevancia y la competencia de la teología práctica y sistemática (KLEIN, 1994). ${ }^{11}$ En la localización de su reflexión,

\footnotetext{
${ }^{10}$ Cabe aclarar que, en la misma serie, se manifiesta una incomodidad por parte de Elizabeth Phillips ante el uso del término, al entender que "la etnografía es un estudio extraordinariamente comprehensivo y holístico de la cultura, que requiere varios meses si no años dedicados a adentrarse en una cultura" y considerar que "cuando teólogas y teólogos usan el término para describir una breve viñeta histórica hasta un estudio teológico de caso, me temo que están confundiendo las cosas más que aclarándolas" (PHILIPS, 2012, p. 102).

${ }^{11}$ La obra presenta un estudio de caso que pone de manifiesto la fecundidad de su método y la historia de vida propuesta en anexo (KLEIN, 1994, p. 171-288, 303-350), pero su consideración excede el espacio de este artículo.
} 
la autora asume como fundamentos la dignidad de la persona humana de la teología del Concilio Vaticano II, la dignidad de los pobres en la perspectiva de la teología de la liberación y la dignidad de las mujeres desde el aporte de la teología feminista. En su visión, la teología feminista se encuentra entre las teologías más consecuentes en cuanto a partir de la vida concreta, de diversas situaciones y experiencias: "la vida y la fe de las mujeres está en el centro de interés" (KLEIN, 1994, p. 60). De tal manera, sostiene la autora, que también los intereses y los comportamientos de los varones son un foco de atención y requieren ser reflexionados, en tanto que ellos determinan la vida de las mujeres en sus relaciones con ellas, la cultura y las estructuras sociales. Así, la teología feminista esclarece el interés y la meta de su conocimiento y su praxis, que no es otro que la liberación de las mujeres, conforme a su dignidad humana, tal como lo ha explicitado el Vaticano II (VELEZ, 2016a; BACHER MARTÍNEZ, 2020). En orden a clarificar el marco conceptual, junto al de androcentrismo, Klein propone examinar el de antropocentrismo, que sirve para expresar una característica esencial de la religión y la cultura judeo-cristiana: lo humano está en el centro, pero está identificado con experiencias e interpretaciones masculinas que se proponen como de valor general, dado que los varones tuvieron y tienen el monopolio de la interpretación y la construcción de la teoría. Algo semejante puede decirse del magisterio y la dogmática formulada por varones, de la cultura y la ciencia con sesgo androcéntrico, que excluye a las mujeres mediante diversos procesos de invisibilización o marginalización. La paradoja de una realidad construida de modo androcéntrico es explicada por la teóloga alemana siguiendo los aportes de diversas teólogas pioneras, al explicitar que, si bien en la sociedad y en la Iglesia se afirma formalmente la igualdad, en la práctica se legitima la desigualdad mediante una naturaleza diferenciada, es decir, varones y mujeres son vividos de manera diferente (KLEIN, 1994, p. 61). ${ }^{12}$ Para liberarse de la visión androcéntrica de lo real que han recibido e interiorizado, las mujeres solo pueden referirse a su vida y a sus experiencias como camino hacia su propia identidad y diferencia:

Un camino de liberación de este sistema, que determina la vida en su totalidad de una manera tan absoluta, puede darse conforme a dos cosas: que las mujeres articulen sus experiencias, que vean y reflexionen su vida, y que se relacionen entre ellas. En este proceso, la narración y la reflexión de la propia historia de vida y de la historia de vida de otras mujeres tiene un significado central. De este modo, las mujeres salen de la invisibilidad y la marginalidad: se ven a sí mismas, se hacen visibles y se ubican en el centro. Aprenden a comprenderse como valiosas. En la medida que articulan sus sentimientos, sus

${ }^{12}$ Klein retoma las obras de Mary Daly, Beyond God the Father (1973), Rosemary Radford Ruether, Sexism and God-Talk (1983) y Elisabeth Schüssler Fiorenza, In Memory of Her (1983) en su edición alemana de 1986, 1985, 1988. El influjo de estas obras está referido por otras teólogas (MEYER-WILMES, 1990; CHOPP, 1991; FULKERSON, 1994). 
vivencias y experiencias, sus deseos e intereses, y reflexionan juntas con una meta de liberación, comienzan a liberarse de la interpretación de la vida según los modelos androcéntricos (KLEIN, 1994, p. 62).

Según el planteo hecho por Stephanie Klein, queda claro el talante crítico y transformativo de la teología feminista, la cual es entendida como una Befreiungstheologie, una teología de la liberación, que parte de la vida y de la fe de las mujeres para impulsar su liberación. La crítica de la teología feminista se dirige hacia las teorías y las formas de lenguaje universalizantes, que omiten, olvidan o dejan desaparecer los diferentes modos de experiencias de mujeres, puesto que una forma de desenvolvimiento del pensamiento androcéntrico es la absolutización de lo masculino por medio de generalizaciones: "detrás de las generalizaciones desaparece el origen de un conocimiento conformado a la medida del androcentrismo" (KLEIN, 1994, p. 64). Lo problemático y opresivo de esta realidad es que, en lo pretendidamente general y universal, las mujeres no pueden verse reflejadas a sí mismas y sus experiencias (KLEIN, 2003). Para la autora, las teólogas feministas exigen la renuncia a las pretensiones de neutralidad y generalización; a cambio, ellas buscan teorías limitadas y contextuadas que se desarrollen a partir de experiencias concretas de mujeres y en las cuales no se pierda lo específico de tales experiencias. Este es el contexto en el cual se muestra la pertinencia del método cualitativo en la teología feminista, por cuanto mediante esta forma de investigación puede accederse, de forma diferenciada, al punto de vista de las mujeres en su diversidad y el relato de sus experiencias puede ser narrado.

El talante crítico de esta teología feminista se profundiza en relación con la hermenéutica crítica feminista, cuya propuesta más destacada es la "memoria peligrosa" de las mujeres en la tradición bíblica, en diálogo con Elisabeth Schüssler Fiorenza. Klein plantea que la teología de la liberación pudo apoyarse en la tradición bíblica para fundamentar la acción de Dios del lado de los pobres y que cuando las mujeres buscaron apoyo en la tradición para afirmar la acción salvadora de Dios con respecto a ellas, se encontraron con una tradición androcéntrica que básicamente refuerza la presencia de salvación para los varones (KLEIN, 1994, p. 65). Si bien este argumento podría al menos matizarse -y la misma autora lo hace- con estudios como el de Luise Schottroff, Lydia's Impatient Sisters (Louisville, Kentucky 1995), la cual recupera una tradición de mujeres judías humilladas y exaltadas que llega hasta el Magnificat, es verdad que en términos generales la afirmación es acertada y muestra una dificultad fundamental:

La experiencia actual de las mujeres en su desvalorización, marginalización y ser invisibilizadas se constata también en la tradición y duplica sus sufrimientos, por cuanto esta visión androcéntrica es entendida como revelación de Dios. En muchos textos, la opresión de las mujeres o la violencia hacia las mujeres es legitimada de forma explícita y estos textos son citados, una y otra vez, para justificar la dominación sobre las mujeres. Naturalmente que hay también 
huellas, que hablan de la liberación de las mujeres y del poder de las mujeres, pero son infrecuentes y muestran a menudo reelaboraciones androcéntricas. Las mujeres como llamadas por Dios, sujetos de fe y de una acción constructora del mundo apenas aparecen (KLEIN, 1994, p. 65).

La cita que hace Klein de E. Schüssler Fiorenza remite a su obra In Memory of Her, en la cual se ofrece una aproximación a una hermenéutica feminista crítica de liberación que dialoga con las luchas de las mujeres por su liberación en el presente y con las hermanas que han sido víctimas de la cultura patriarcal en el pasado. La posición no es abandonar la memoria de las antecesoras de las mujeres que luchan hoy, sino reclamar la fuerza subversiva de una "memoria peligrosa", que no solo mantenga vivo el recuerdo del sufrimiento y la esperanza de las mujeres en el pasado, sino que posibilite una solidaridad universal de hermanas con todas las mujeres de pasado, presente y futuro que siguen la misma visión. La teóloga católica rumana hace cita, en este contexto, de J.-B. Metz para recordar que se trata de una memoria passionis, mortis et resurrectionis, es decir, que mantiene viva la memoria del sufrimiento de las mujeres y a la vez reclama su herencia religiosa y teológica, tanto de opresión como de liberación (SCHÜSSLER FIORENZA, 2000, p. 31.36). De este modo, la escucha de las experiencias de sufrimiento y esperanza de las mujeres se realiza junto a la escucha y la memoria de sus opresiones y sus luchas en los textos bíblicos.

\subsubsection{Del hearing to speech de Nelle Morton a la "escucha peligrosa"}

En un artículo de 2003, Stephanie Klein desmenuza el valor del método cualitativo en la teología feminista, al proponerse descifrar la experiencia de las mujeres y descubrir nuevas categorías teológicas en conversación con la teóloga católica norteamericana Nelle Morton. El punto de partida es el par conceptual de "memoria y narración" tomado de Johann Baptist Metz, pero enriquecido con la introducción del concepto de Geschlechterdifferenz (diferencia sexual) para hacer frente a la perspectiva androcéntrica general. ${ }^{13}$ Retomando análisis anteriores sobre las prácticas de narración y escucha de experiencias de mujeres (KLEIN, 1998), la autora puntualiza que la mayor dificultad está en que ellas no disponen de un lenguaje adecuado, de un mundo simbólico propio, para articular su experiencia. Sólo cuando las mujeres dejan de ser una diferencia secundaria y pasan a comprenderse como una diferencia primaria, se abren caminos para pensar, hablar y subjetivar de otro modo. Con otras palabras, se trata de desen-

${ }^{13}$ La autora cita el artículo de A. Caravero, Ansätze zu einer Theorie der Geschlechterdifferenz. In Diotima: Philosophinnengruppe aus Verona, Der Mensch ist zwei: Das Denken der Geschlechterdifferenz, p. 65-102. Wien: Wiener Frauenverlag, 1993. 
trañar, mediante el instrumental de la teoría feminista, la desigualdad que se afianza a partir de la diferencia que representa ser mujer frente al varón, en una sociedad androcéntrica o kyriarcal (KLEIN, 2003, 2019; BEDFORD, 2005; AMMICHT-QUINN, 2017).

En su reflexión, Klein recupera un aporte de Nelle Morton, quien buscó caminos para que las mujeres pudieran expresar sus experiencias en un lenguaje propio y se apoyó en una práctica con grupos de mujeres, que se manifestó como transformadora en el escucharse mutuo. ${ }^{14}$ La fórmula en inglés hearing to speech de N. Morton, traducida al alemán por Klein como Hören als Ermächtigung zum Sprechen, puede entenderse como la práctica de una escucha que empodera para hablar. El paso importante de Klein es seguir a Morton al comprender esta práctica como una categoría fundamental de la liberación de las mujeres y reflexionar sobre los nuevos modos de conocimiento teológico que surgen de ella (KLEIN, 2003 , p. 820). La propuesta de la autora se inscribe en un intento de hacer teología a partir de la experiencia liberadora de las mujeres y como ejercicio crítico hacia la universalidad de una teología que se manifiesta androcéntrica. En la exposición de su pensamiento, Klein abarca diversos temas y aspectos como el punto de partida del conocimiento teológico, Dios como el/la que escucha, el hablar de Dios y el anuncio evangelizador entendido como escucha, un renovado estilo de acompañamiento espiritual, el hearing to speech como categoría de liberación de mujeres y también de varones, y la pregunta por una teología de totalidad. De este conjunto, se selecciona la cuestión de Dios y la "escucha peligrosa" de la experiencia de las mujeres para presentar su reflexión en forma breve, aunque cada uno de los elementos propuestos por la autora daría lugar para ser comentado.

Con respecto a la cuestión de Dios, central en toda teología, Klein intenta profundizar en la relación entre la palabra de Dios y la vida de las mujeres, un tema de valor permanente en las teologías feministas. De acuerdo a la práctica del hearing to speech, la teóloga práctica sostiene que el conocimiento teológico -práctico, inductivo o empírico- no surge de la palabra de Dios, sino de la escucha de Dios a la teóloga y de la escucha de esta, a su vez, de otras mujeres. Dios es contemplado y comprendido como el/la que escucha (KLEIN, 2003, p. 826), una metáfora que otras teólogas y teólogos han aplicado a la acción del Espíritu Santo, la escucha de la Palabra en persona. Dicho de otro modo, Dios recibe a mujeres y varones despertando

\footnotetext{
${ }^{14}$ Nelle Morton (1905-1987) estudió teología en New York y Genf; fue profesora en la Facultad de Teología de la Universidad de Drew (EE.UU.); activista por los derechos civiles, la paz, los derechos humanos y la liberación de las mujeres. Por razones de espacio no presento la narración sobre el descubrimiento del hearing to speech, inspirado en el testimonio de una mujer en los grupos acompañados por Nelle Morton y relatado por ella al final de su vida en la obra The Journey is Home (Boston 1985) (KLEIN, 2003, p. 821ss).
} 
en cada una/o su mensaje en su propio lenguaje; la práctica de la escucha que suscita el hablar empoderado de las mujeres abre nuevas perspectivas para pensar la acción de Dios y sobre todo el lugar de Su escucha liberadora. El planteo no podría ser más sugerente, aunque el límite de este artículo no permite su problematización: un anuncio entendido como una forma de escucha y un recibir a la otra/o como una forma de animar al propio lenguaje, en coherencia además con una teología de los signos de los tiempos que requiere de la escucha como práctica fundamental de la Iglesia (KLEIN, 2014). Queda planteado un tema fundamental: cómo se relaciona la experiencia de las mujeres con la Palabra de Dios, la escucha de Dios a la humanidad, que incluye a las mujeres y el hablar sobre Dios, a partir de sus vidas. El aporte de la teología feminista, en este punto, parece realmente insoslayable...

El segundo tema elegido se centra, precisamente, en la consideración del hearing to speech como categoría de liberación, es decir, como un proceso de empoderamiento mutuo y de liberación de las mujeres que cambia las estructuras sociales. En este punto, Klein sigue a Johann Baptist Metz para elaborar el concepto de una "escucha peligrosa", según la triada memoria, narración y solidaridad, que ha sido motivo de diversas relecturas por parte de teólogas feministas. Con palabras de Rebecca Chopp, la teología usa la narrativa "para recuperar la tradición cristiana, para narrar las memorias peligrosas del sufrimiento y para efectuar conversión y transformación" (CHOPP, 1986, 140). En el caso de Elizabeth Johnson, siguiendo la triada de Metz,

quienes han sido no personas se convierten en sujetos activos de la historia a través de la memoria narrativa de las experiencias de sufrimiento y de fracaso, así como de resistencia y victoria, y a través de la solidaridad en medio de la refriega histórica. (...) En esta dimensión profundamente religioso-personal es donde las mujeres se encuentran con nuevas experiencias que, al ser articuladas, desembocan en un nuevo lenguaje sobre Dios (JOHNSON, 2002 [1992], p. 96).

De manera semejante, en la visión narrativa de Stephanie Klein, el dolor, los anhelos y las esperanzas, al ser expresados, crean un nuevo lenguaje: "Las oprimidas y los oprimidos son empoderadas/os y se empoderan mutuamente" (KLEIN, 2003, p. 829). En la visión teológica práctica de la autora, emerge una formulación nítidamente inclusiva, al indicar que mujeres y varones pueden ser colaboradoras/es en un proceso de mutua liberación, como ya dos décadas antes lo había propuesto la teóloga presbiteriana Letty M. Russell en su visión antropológica de nuevas relaciones de partnership o cooperación. Vale decir que la escucha mutua se puede aplicar a la relación entre mujeres y con varones, en la perspectiva de la reciprocidad capaz de superar toda forma de relación opresiva, que subordina, en otras que liberan y empoderan haciendo posible el advenimiento de la palabra de salvación que da vida. De nuevo en sintonía con Russell, Klein recuerda que en este punto nos movemos en el horizonte de un 
futuro escatológico, próximo a la visión judeo-cristiana del Shalom (paz), que requiere ser tomado en serio para poder ser construido en el tiempo presente. Para poder articular una teología de totalidad, que sea inclusiva de mujeres y varones, lo universal debe ser pensado incorporando la diferencia sexual; se trata siempre de una universalidad en la diferencia, que hace justicia a las diferencias sexo-genéricas.

\subsubsection{El desafío de hospedar la diferencia sexual en la teología cristiana}

La contribución metódica de Stephanie Klein constituye un caso ejemplificador del cruce entre el método cualitativo en teología y la hermenéutica crítica feminista. Los aspectos de su obra elegidos para dialogar en este estudio abren diversas perspectivas de reflexión que podrían profundizarse: una de ellas es el legado del Concilio Vaticano II y de Gaudium et spes que, al plantear el desafío de la dignidad humana, ha generado teologías contextuales que señalan lugares teológicos y sujetos eclesiales a priorizar (COSTADOAT, 2005; VELEZ, 2016a; SCHICKENDANTZ, 2018). De particular interés son las diversas incursiones de Klein en torno al método ver-juzgar-obrar y su doble nexo con el método cualitativo en teología y la lectura de los signos de los tiempos (KLEIN, 1994, 2014). En efecto, como señala el sociólogo Manuel Canales, este nexo queda en evidencia desde el momento que "mientras los investigadores cuantitativos miden, los investigadores cualitativos auscultan -en su origen, inclinar el oído-" (2014, p. 11).

En este contexto, la perspectiva crítica que introduce el feminismo concentra su mirada en las experiencias de opresión y liberación en un contexto androcéntrico solapado con frecuencia detrás de un pretendido antropocentrismo universal. Tanto la diferencia sexual como la perspectiva de género son herramientas conceptuales básicas para desmantelar las distorsiones socio-religiosas producidas por el sesgo patriarcal o masculino-dominante. Lo que Klein muestra y desarrolla es que también son necesarias las prácticas para que se dé la transformación esperada $\mathrm{y}$, entre ellas, destaca -en diálogo con otras teólogas/os- la prioridad de una escucha que empodere a las mujeres, que les permita narrarse y ser sí mismas. La experiencia de estas mujeres que son hospedadas y escuchadas por otras/os, para retomar la propuesta de Swinton-Mowat (2006), está en la base de una renovación del discurso teológico: la vida de las mujeres es reconocida como lugar teológico, historias de vida e historias de fe son un ámbito en el cual se puede auscultar la Palabra de Dios en el tiempo presente (KLEIN, 2003; CHOPP, 1995; AZCUY, 2003; BECERRA, 2015).

La propuesta de una "escucha peligrosa" -inspirándose en J.-B. Metz y en las relecturas de diversas teólogas feministas como Schüssler Fiorenza, 
Chopp y Johnson, entre otras- pone de manifiesto la mutua potenciación que se da entre el uso del método cualitativo y la perspectiva crítica feminista. También señala la convergencia entre la teología feminista y la teología de los signos de los tiempos, orientada a auscultar los signos y las voces de Dios en la historia. La contribución de Stephanie Klein merece ser profundizada más allá de este artículo, por cuanto desafía a una escucha hospitalaria e inclusiva de las diferencias sexo-genéricas en diversas teologías.

\section{Reflexión final: la teología feminista como un "pensar peligroso"}

Situada en el límite, la teología feminista se mantiene en contacto estrecho con la Biblia y las diversas experiencias de mujeres desde una perspectiva crítica (MEYER-WILMES, 1990). Mediante el instrumental de la teoría feminista, se confronta con el androcentrismo en su pretendida universalidad que no es más que la parcialidad del universo masculino. Se distancia de un discurso universal esencialista sobre la mujer y busca, en cambio, auscultar esa universalidad diferenciada en un grupo de mujeres o en historias de vida de mujeres (JONES, 1997; KLEIN, 1994; AZCUY, 2003; BACHER MARTÍNEZ, 2020). Como otras teologías que se inspiran en el Concilio Vaticano II, las teologías feministas cristianas desarrollan un modo de teologizar marcado por lo práctico, lo contextuado y lo experiencial, en el caso de la teología feminista vinculado con la diversidad de experiencias de mujeres (FULKERSON, 1994; CHOPP, 2002, 1995). Asumen el método ver-juzgar y obrar, intentan leer la opresión y la liberación de las mujeres como un signo de los tiempos y discernir, junto a Dios que habla y escucha, la palabra proclamada a través de la vida de las mujeres (AQUINO; TAMEZ, 1998; KLEIN, 2005; BACHER MARTÍNEZ, 2017).

La peculiaridad de la teología feminista está en el recurso a la teoría feminista, en comprenderse a sí misma en la frontera entre el cristianismo y el feminismo, volviéndose así un "pensar peligroso" capaz de hacer memoria de la opresión y la liberación de las mujeres, de escuchar y empoderar a las mujeres para narrar sus historias y hablar de Dios con un lenguaje nuevo (KLEIN, 2003). El uso de la metodología cualitativa, que asume la perspectiva de los actores sociales o religiosos, en especial de quienes son considerados sin voz o sin poder de enunciación -en este caso las mujereses también, por naturaleza, subversivo en tanto busca lecturas "desde el lugar de las víctimas" y sus "luchas de liberación" (CHOPP, 1986; ISASI, 1993; VIVAS, 2001). De manera que la forma de investigación cualitativa, que se define como cooperativa, no puede sino resultar adecuada para una teología que se ocupa de "lo peligroso", esto es, las cuestiones de 
sexo-género (AMMICHT-QUINN, 2012; PINEDA-MADRID, 2017). Las ejemplificaciones presentadas en este artículo, en especial las teologías de Ada María Isasi-Díaz, Rebecca Chopp y Stephanie Klein, resultan inspiradoras para el quehacer teológico de las mujeres en América Latina y el Caribe, que también se ubica en los bordes o las fronteras de diferentes espacios sociales, eclesiales y académicos. Un indicador elocuente, al respecto, se percibe en la preferencia de teólogas de distintas generaciones y diversos países por asumir periferias existenciales, para hacer relevamientos empíricos mediante distintas prácticas de "escucha peligrosa" (AZCUY, 2018a; BECERRA MELO, 2018).

Tanto para las teologías hechas por mujeres como para las escritas por varones en nuestro contexto, la memoria solidaria del sufrimiento humano y la escucha hospitalaria de los relatos de quienes buscan liberación, son caminos fundamentales en el punto de partida del discurso teológico. El uso de la investigación cualitativa en teología resulta una mediación oportuna, casi indispensable, para la recuperación de memorias de sufrimiento y relatos de liberación de las mujeres. En su cruce con la teología feminista, este método también puede resultar de crucial importancia para la escucha requerida en los procesos sinodales que transita la Iglesia actual en América Latina y el Caribe.

\section{Referencias}

AMEIGEIRAS, A. R. El abordaje etnográfico en la investigación social. In: VASILACHIS DE GIALDINO, I. (Ed.). Estrategias de investigación cualitativa. Barcelona: Gedisa, 2012. p. 107-151.

AMMICHT-QUINN, R. Pensar peligroso, pensar lo peligroso: género y teología. Concilium, Madrid, n. 347, p. 483-498. 2012.

AMMICHT-QUINN, Gender. Zur "Grammatik" der Geschlechterverhältnisse. In: ECKHOLT, M. (Ed.). Gender studieren. Lernprozess für Theologie und Kirche. Ostfildern: Grünewald, 2017. p. 23-38.

AQUINO, M. P.; TAMEZ, E. Teología Feminista Latinoamericana. Quito, Ecuador: Abya-Yala, 1998. (Serie: Pluriminor).

AQUINO, M. P.; MACHADO, D. L.; RODRÍGUEZ, J. (Ed.). A Reader in Latina Feminist Theology. Religion and Justice. Austin: University of Texas, 2002.

AZCUY, V. R. Teologías desde las biografías de las mujeres. Reflexiones sobre el método. In: SCHICKENDANTZ, C. (Ed.), Mujeres, género y sexualidad. Una mirada interdisciplinar. Córdoba: EDUCC, 2003. p. 193-232.

AZCUY, V. R. La entrevista en el estudio teológico de la espiritualidad. Presupuestos epistemológicos, investigación cualitativa y aportes de una técnica. Teología, Buenos Aires, v. LIII, n. 121, p. 73-98, 2016. 
AZCUY, V. R. Introducción: Teologizar prácticas de espiritualidad popular en espacios urbanos. In: AZCUY, V. R. (Ed.). Teología urbana: prácticas de espiritualidad popular. Buenos Aires: Ágape Libros, 2018a. p. 11-16.

AZCUY, V. R.; BEDFORD, N. E.; GARCIA BACHMANN, M. Teología feminista a tres voces. Santiago: Ediciones Universidad Alberto Hurtado, 2018b.

BACHER MARTÍNEZ, C. Zarzas que arden. Aportes del estudio teológico-pastoral de caso a una teología de los signos de los tiempos. In: AZCUY, V. R.; SCHICKENDANTZ, C.; SILVA, E. (Ed.). Teología de los signos de los tiempos latinoamericanos. Horizontes, criterios y métodos. Santiago: Ediciones Universidad Alberto Hurtado, 2013. p. 389-410.

BACHER MARTÍNEZ, C. Aportes de la investigación-acción participativa a una teología de los signos de los tiempos en América Latina. Theologica Xaveriana, Bogotá, v. 67, n. 184, p. 309-332, jul./dic. 2017.

BACHER MARTÍNEZ, C. Ana María Bidegain Greising. Tras la búsqueda de una historia de la Iglesia liberadora y feminista. In: AZCUY, V. R.; ORTIZ DE ELGUEA, E.; RAIMONDO, N. (Ed.). Travesías de teólogas feministas pioneras. Córdoba: Ediciones Universidad Católica de Córdoba, 2020. p. 151-162.

BECERRA MELO, S. El arte de reiniciar la vida: una mirada de género. ¿Cómo experimenta la salvación de Dios, la mujer víctima de la violencia? Bogotá: Pontificia Universidad Javeriana, 2015.

BECERRA MELO, S. La espiritualidad en pacientes que viven con VIH. Revista Cuestiones Teológicas, Medellín, v. 45, n. 103, p. 149-175, enero/jun. 2018.

BEDFORD, N. E. Dar razón de la fe que hay en nosotras. Elementos del feminismo como mediación socio-analítica para la teología latinoamericana. Proyecto, Buenos Aires, n. 39, p. 145-161, 2001.

BEDFORD, N. E. Presentación: Puntos de apoyo de los Puntos de encuentro. In: BEDFORD, N. E.; GARCIA BACHMANN, M.; STRIZZI, M. (Ed.). Puntos de encuentro. Buenos Aires: Instituto Universitario ISEDET, 2005. p. 13-35.

BIRD, P. Feminism and the Bible: a Critical and Constructive Encounter. Winnipeg, Manitoba: Canadian Mennonite Bible College Publishers, 1994.

CANALES, M. (Coord.). Escucha de la escucha. Análisis e interpretación en la investigación cualitativa. Santiago: LOM Ediciones, 2014.

CERDA-PLANAS, C. Las potencialidades de la Teología Empírica para el desarrollo de una teología en diálogo con la experiencia religiosa actual. Teología y Vida, Santiago, v. 60, n. 3, p. 367-394, 2019.

CHOPP, R. S. The Praxis of Suffering: an Interpretation of Liberation and Political Theologies. Maryknoll, NY: Orbis Books, 1986.

CHOPP, R. S. The Power to Speak: Feminism, Language, God. Oregon: Wipf and Stock Publishers, 2002 (1991).

CHOPP, R. S. Saving Work: Feminist Practices of Theological Education. Louisville, Kentucky: Westminster John Knox Press, 1995. 
COSTADOAT, J. La hermenéutica en las teologías contextuales de la liberación. Teología y Vida, Santiago, v. XLVI, n. 1 y 2, p. 56-74, 2005.

FLORES G., R. Observando Observadores: una introducción a las Técnicas Cualitativas de Investigación Social. Santiago: Pontificia Universidad Católica de Chile, 2009.

FULKERSON, M. M. Changing the Subject: Women's Discourses and Feminist Theology. Eugene, Oregon: Wipf and Stock Publishers, 1994.

FULKERSON, M. M.; BRIGGS, S. (Ed.). The Oxford Handbook of Feminist Theology. Oxford: Oxford University Press, 2012.

ISASI-DÍAZ, A. M. En la lucha: elaborating a mujerista theology. Minneapolis: Fortress Press, 1993.

ISASI-DÍAZ, A. M. Mujerista Theology: a Theology for the Twenty-First Century. Maryknoll, New York: Orbis Books, 1996.

JOHNSON, E. A. La que es: el misterio de Dios en el discurso teológico feminista. Barcelona: Herder, 2002 (1992).

JONES, S. Women's Experience between a Rock and a Hard Place. Feminist, Womanist, and Mujerista Theologies in North America. In: CHOPP, R. S.; GREEVE DAVANEY, S. (Ed.). Horizons in Feminist Theology: Identity, Tradition, and Norms. Minneapolis: Fortress Press, 1997. p. 33-53.

KLEIN, S. Theologie und empirische Biographieforschung. Methodische Zugänge zur Lebens- und Glaubensgeschichte und ihre Bedeutung für eine erfahrungsbezogene Theologie. Stuttgart - Berlin - Köln: Verlag W. Kohlhammer, 1994.

KLEIN, S. Von den Erfahrungen von Frauen zu feministischer Theologie. Hören und Erzählen als Ermächtigung zu neuem Sein von Frauen und zu einer neuen Rede von Gott. In: MEYER-WILMES, H.; TROCH, L.; BONS-STORM, R. (Ed.), Feministische Perspektiven in Pastoraltheologie (Jahrbuch de Europäischen Gesellschaft für theologische Forschung von Frauen 6). Mainz/Leuven: Grünewald/Peeters 1998. p. 47-71.

KLEIN, S. Erschliessung der Erfahrung von Frauen und die Entdeckung neuer theologischer Kategorien. HTS Teologiese Studies/Theological Studies, Afrikaans, v. 59, n. 3, p. 811-836. 2003.

KLEIN, S. Erkenntnis und Methode in der Praktischen Theologie. Stuttgart: Verlag W. Kohlhammer, 2005.

KLEIN, S. Die vielschichtige Rede von den Zeichen der Zeit. Anmerkungen zu einem Ortswechsel theologischer Erkenntnis und diakonisch-pastoraler Praxis. Pastoraltheologische Informationen, Münster, v. 34, n. 1, p. 25-36. 2014.

KLEIN, S. Observations of Developments in the Debate on Gender in Society and Theology. Anmerkungen zu Entwicklungen der Diskussion um die Genderfrage in der Gesellschaft und Theologie. O rozwoju dyskusji woköt tematyki gender na plaszczyznie spolecznej i teologicznej. In: ROGOWSKI, C.; SPIEGEL, E.; STROSS, A. M.; LEHNER-HARTMANN, A.; MARIANSKI, J. (Ed.), Gender. Keryks: Religious-Pedagogical Forum - Religionspädagogisches Forum - Forum Fedagogicznoreligijne 2015-2018. Berlin 2019. p. 45-66. 
MEYER-WILMES, H. Rebellion auf der Grenze: Ortbestimmung Feministischer Theologie. Freiburg / Basel / Wien: Herder, 1990.

MEYER-WILMES, H. Zwischen lila und lavendel. Schritte feministischer Theologie. Regensburg: Verlag Friedrich Pustet, 1996.

PHILLIPS, E. Charting the Ethnographic Turn: Theologians and the Study of Christian Congregations. In: WARD, P. (Ed.). Perspectives on Ecclesiology and Ethnography. Grand Rapids, Michigan: Eerdmans Publishing Company, 2012. p. 95-106.

PINEDA-MADRID, N. La teoría feminista y la teologización feminista/mujerista Latina: ¿qué hay en un nombre? In: ARANGUREN GONZALO, L.; PALAZZI, F. (Ed.). Desafíos de una teología iberoamericana inculturada en tiempos de globalización, interculturalidad y exclusion social. Boston, Massachusetts: Boston College, 2017. p. 396-404.

RAIMONDO, N. V. De mapas teológicos y travesías vitales en las teologías feministas. In: AZCUY, V. R.; ORTIZ DE ELGUEA, E.; RAIMONDO, N. (Ed.). Travesías de teólogas feministas pioneras. Córdoba: Ediciones Universidad Católica de Córdoba, 2020. p. 13-35.

RESS, M. J. Ecofeminism in Latin America. Women from the Margins, Maryknoll, NY: Orbis Books, 2012 (2003).

RUETHER, R. R. Sexism and God-Talk: Toward a Feminist Theology. Boston: Beacon Press, 1993 (1983).

RUETHER, R. R. Women-Church: Theology and Practice of Feminist Liturgical Communities. San Francisco: Harper \& Row, Publishers, 1985.

SCHICKENDANTZ, C. La naturaleza teológica del momento inductivo. En tiempos de diversidad, pluralismo y alteridad cultural. Veritas n. 38, p. 99-120, 2017.

SCHICKENDANTZ, C. El teologar sinodal. Interacción dialéctica de lugares teológicos y sujetos eclesiales. CrSt, n. 39, p. 441-469, 2018.

SCHÜSSLER FIORENZA, E. In Memory of Her: a Feminist Theological Reconstruction a of Christian Origins. New York: The Crossroad Publishing Company, 2000 (1983).

SCHÜSSLER FIORENZA, E. Changing Horizons: explorations in Feminist Interpretation. Minneapolis: Fortress Press, 2013.

SOMMER, R. Lebensgeschichte und gelebte Religion von Frauen. Eine qualitativ-empirische Studie über die Zusammenhang von biographischer Struktur und religiöser Orientierung. Stuttgart / Berlin / Köln: Verlag W. Kohlhammer, 1998.

SWINTON, J. "Where Is Your Church?" Moving toward a Hospitable and Sanctified Ethnography. In: WARD, P. (Ed.). Perspectives on Ecclesiology and Ethnography. Grand Rapids, Michigan: Eerdmans Publishing Company, 2012. p. 71-92.

SWINTON, J.; MOWAT, H. Practical Theology and Qualitative Research. London: SCM Press, 2006.

VASILACHIS DE GIALDINO, I. (Ed.). Estrategias de investigación cualitativa. Barcelona: Gedisa, 2012. 
VELEZ CARO, O. C. La teología feminista. In: El método teológico: fundamentos, especializaciones, enfoques. Bogotá: Pontificia Universidad Javeriana, 2008 (2000). p. 226-284.

VELEZ CARO, O. C. El nuevo teologizar a partir del Vaticano II. Kénosis, Rionegro, 4, n. 6, p. 15-25, enero/jun. 2016a.

VELEZ CARO, O. C. El quehacer teológico y el método de investigación acción participativa. Teológica Xaveriana, Bogotá, v. 67, n. 183, p. 187-208, enero/jun. 2016b.

VIVAS, M. S. Mujeres que buscan liberación. Identidad de la mujer. Bogotá: Pontificia Universidad Javeriana, 2001.

VUOLA, E. Teología feminista; teología de la liberación: los límites de la liberación, la praxis como método de la teología latinoamericana de la liberación y de la teología feminista. Madrid: Iepala, 2000.

WARD, P. (Ed.). Perspectives on Ecclesiology and Ethnography. Grand Rapids, Michigan / Cambridge, U.K.: William B. Eerdmans Publishing Company, 2012.

Artículo sometido en 18.08.2021 y aprobado en 20.11.2021.

Virginia Raquel Azcuy es Doctora en Teología por la Facultad de Teología de la Pontificia Universidad Católica Argentina (1996) y Profesora titular (2003). Investigadora en el Centro Teológico Manuel Larraín, por la Facultad de Teología de la Pontificia Universidad Católica de Chile (2010). Orcid.org/0000-0001-5462-2065. Mail: raqazvi@gmail.com

Dirección: Cafayate 4267 / C1439FUE

Ciudad Autónoma de Buenos Aires, Argentina 